\title{
Systemic Lupus Erythematosus mimicking lymphoproliferative malignancy in a child
}

\author{
Munasinghe TM, ${ }^{1}$ Naotunna $\mathrm{C},{ }^{1}$ Vithana $\mathrm{S},{ }^{1}$ Kankananarachchi $\mathrm{I},{ }^{2}$ Dharmawardena $\mathrm{H},{ }^{1}$ Amarasena $\mathrm{S}^{2}$ \\ 1. Teaching Hospital Karapitiya \\ 2. Faculty of Medicine, University of Ruhuna
}

Corresponding Author:

Kankananarachchi I, Faculty of Medicine, University of Ruhuna

\begin{abstract}
Systemic Lupus Erythematosus (SLE) is a chromic autoimmune disease with multisystemic involvement. The estimated prevalence of SLE among children is 1-6/100000. Here we report a child who presented with generalized lymphadeopathy as the first manifestation of SLE. A 13 year old previously healthy girl presented with cervical lymphadenopathy and low grade remitting fever for 1 month duration. On examination she was found to have generalized lymphadenopathy and unremarkable rest of the clinical examination. Her basic haematological and biochemical parameters were normal. ESR was $110 \mathrm{~mm} / \mathrm{hr}$ and CRP was $6 \mathrm{mg} / \mathrm{dL}$. Ultrasound scan and Contrast CT of the abdomen and pelvis revealed extensive mediastinal, mesenteric, para-aortic, splenic hilar, bilateral axillary and inguinal lymphadenopathy suggestive of lymphoproliferative malignancy. However, her bone marrow and lymph node biopsies revealed reactive pattern. Meantime she developed a malar rash, oral ulcers and 2 episodes of generalized tonic-clonic convulsions. Her urinalysis revealed microscopic haematuria and sub nephrotic range proteinuria. Her ANA and dsDNA levels were positive. Her subsequent full blood count revealed severe bicytopenia, predominetly lymphopenia.The diagnosis of SLE was made and she was started on Hydroxychloroquine, high dose prednisolone and cyclophosphamide pulse therapy.
\end{abstract}

The most common presenting symptoms of SLE in children include, constituitional symptoms, joint symptoms and haematological abnormalities. It is estimated $23-34 \%$ children with SLE are having lymphadenopathy. Though, generalized lymphadenopathy as the presenting symptom of SLE is uncommon, it should not be forgotten in order to avoid diagnostic delay.

\section{Introduction}

Systemic Lupus Erythematosus (SLE) is a chromic autoimmune disease with multisystemic involvement. ${ }^{1}$ The estimated prevalence of SLE among children is 3.3 to $8.8 / 100000 .{ }^{2}$ Although, lymphadenopathy is a recognized feature of SLE, generalized lymphadenopathy in isolation is rare presentation of the disease. Here we report a child who presented with generalized lymphadeopathy as the first manifestation of SLE.

\section{Case Report}

A 13-year-old previously healthy girl presented with a neck lump suggestive of cervical lymphadenopathy and low grade remitting fever for 1 month duration. Lymph nodes were multiple, firm, non-tender and freely mobile. Apart from the cervical lymphadenopathy she did not have enlarged lymph nodes in other sites of her body. Rest of her general examination was unremarkable. Her vital 
signs were stable and she did not have organomegaly in the abdominal examination. A comprehensive neurological examination was performed and the findings were unremarkable.

Her initial investigations showed elevated Erythrocyte sedimentation rate (ESR), normal C-Reactive Protein (CRP), microscopic haematuria, proteinuria and normal basic haematological and biochemical parameters. (Table 1) She underwent an ultrasound scan of the abdomen which revealed mesenteric and para aortic lymphadenopathy.

Table 1/nitial investigation summary

\begin{tabular}{|c|c|}
\hline $\begin{array}{l}\text { Full blood count } \\
\text { WBC (Neutophils, Lymphocytes) } \\
\text { Haemoglobin } \\
\text { Platelets }\end{array}$ & $\begin{array}{c}8500(45 \%, 50 \%) \\
10.5 \mathrm{~g} / \mathrm{dL} \\
235\end{array}$ \\
\hline CRP & $6 \mathrm{mg} / \mathrm{dL}$ \\
\hline ESR & $110 \mathrm{~mm} / 1 \mathrm{st} \mathrm{hr}$ \\
\hline AST, ALT & $65 \mathrm{IU} / \mathrm{L}(0-31), 51 \mathrm{IU} / \mathrm{L}(0-34)$ \\
\hline Sodium & $136 \mathrm{mEq} / \mathrm{L}$ \\
\hline Potassium & $4.1 \mathrm{mEq} / \mathrm{l}$ \\
\hline Creatinine & $52 \mu \mathrm{mol} / \mathrm{L}(58-96)$ \\
\hline Blood urea & 34 mg/dL (11-39) \\
\hline $\begin{array}{l}\text { Urinalysis } \\
\text { Pus cells } \\
\text { Red cells } \\
\text { Protein }\end{array}$ & $\begin{array}{c}1-2 / \mathrm{hpf} \\
30-40 / \mathrm{hpf} \\
++\end{array}$ \\
\hline
\end{tabular}

A CT- chest, abdomen and pelvis was performed which demonstrated extensive mediastinal, mesenteric, para aortic, splenic hilar lymphadenopathy suggestive of lymphoproliferative malignancy. Due to the suspicion of lymphoproliferative malignancy she was transferred to the Cancer Institute Maharagama (CIM) for further management. She had undergone bone marrow and lymph node biopsies and revealed reactive pattern. On the second week of CIM stay she developed pancytopenia, malar rash (figure 1) and an oral ulcer in the hard palate (Figure 2). She had two episodes of afebrile convulsions. Subsequently she was transferred back for further evaluation of possible systemic Lupus Erythematosus (SLE).

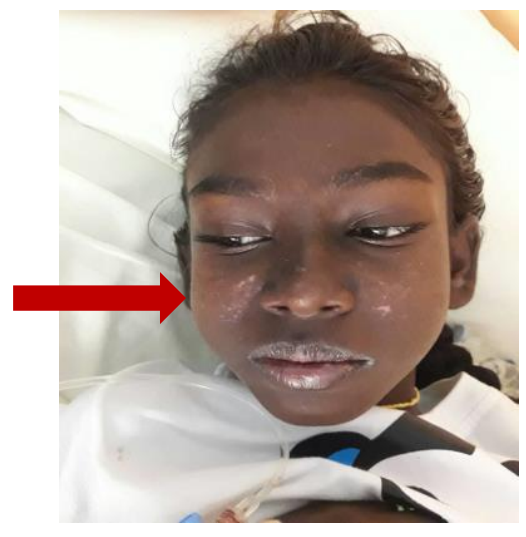

Figure 01 Malar rash

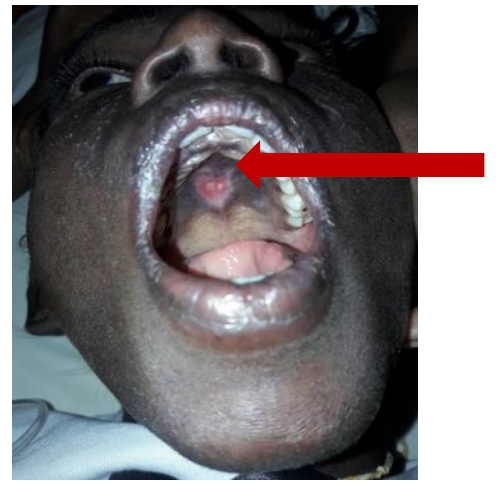

Figure 02 painless oral ulcer 
Her repeat investigations, done 2 weeks apart from the initial investigations showed features suggestive of SLE (Table 2)

Table 2; Subsequent Investigations

\begin{tabular}{|l|c|c|}
\hline & $\begin{array}{c}\text { Before starting } \\
\text { treatment }\end{array}$ & $\begin{array}{c}3 \text { months after } \\
\text { treatment }\end{array}$ \\
\hline $\begin{array}{l}\text { Full blood count } \\
\text { WBC (Neutrophils, Lymphocytes) } \\
\text { Platelets }\end{array}$ & 0.91 (52.9\%, 34.9\%) & 6.5 (58.3\%. 38.9\%) \\
CRP & 6.4 & 8.9 \\
\hline ESR & 245 & 475 \\
\hline AST, ALT & $7 \mathrm{mg} / \mathrm{dL}$ & $<5$ \\
\hline Sodium & $125 \mathrm{~mm} / 1 \mathrm{st} \mathrm{hr}$ & 18 \\
\hline Potassium & $266 \mathrm{U} / \mathrm{L}, 185 \mathrm{U} / \mathrm{L}$ & $61 \mathrm{U} / \mathrm{L}, 42 \mathrm{U} / \mathrm{L}$ \\
\hline Serum Creatinine & $130 \mathrm{mEq} / \mathrm{L}$ & $135 \mathrm{mEq} / \mathrm{L}$ \\
\hline Blood urea & $4.6 \mathrm{mEq} / \mathrm{L}$ & $4.3 \mathrm{mEq} / \mathrm{L}$ \\
\hline Urinalysis $\quad 118 \mu \mathrm{mol} / \mathrm{L}$ & $85 \mu \mathrm{mol} / \mathrm{L}$ \\
$\quad$ Pus cells & $48 \mathrm{mmol} / \mathrm{L}$ & $8.7 \mathrm{mmol} / \mathrm{L}$ \\
\hline$\quad$ Red cells & & $\mathrm{Nil}$ \\
\hline Protein & $3-4 / \mathrm{hpf}$ & $5-6 / \mathrm{hpf}$ \\
\hline Urine protein creatinine ratio & $60-70 / \mathrm{hpf}$ & + \\
\hline ANA & ++ & - \\
\hline dsDNA & 3.51 & - \\
\hline Direct Coomb's test & Positive & \\
\hline
\end{tabular}

She underwent a renal biopsy and the histology revealed Lupus nephritis class III.The diagnosis of SLE was made based on the Systemic Lupus International Collaboration Clinics (SLICC) criteria ${ }^{2}$. According to the criteria, SLE can be diagnosed, if there is biopsy proven lupus nephritis in the presence of positive ANA or anti-DNA. Based on the above findings the diagnosis of SLE was made in this patient and she was started on IV Methylprednisolone $30 \mathrm{mg} / \mathrm{kg} /$ day for 5 days and $O$. Hydroxychloroquinine $(5-6 \mathrm{mg} / \mathrm{kg} / \mathrm{day})$. Intravenous steroid course was followed by monthly IV Cyclophosphamide pulse therapy for 6 months. Following the treatment the cytopenia was the first to improve (Lymphopenia improved following 3 methyl prednisolone doses.) By $3^{\text {rd }}$ month of IV Cyclophosphamide proteinuria was settled and the microscopic haematuriadisappeared.(table 2) During the course of treatment she had increase weight gain but didn't experience any major side effects of the drugs.

\section{Discussion}

SLE is a chronic autoimmune disorder, which is characterized by its relapsing nature, involve almost all systems in the body. ${ }^{1}$ It is predominantly a disease of females and $20 \%$ of cases are diagnosed during the childhood. ${ }^{1}$ The incidence of juvenile SLE is 3.3 to 8.8 per 100000 children. ${ }^{3}$

SLE has a wide array of clinical manifestations that are associated with significant morbidity and mortality. The most common presenting symptoms of SLE in children include, constituitional symptoms, joint symptoms and haematological abnormalities. ${ }^{4}$ It is estimated $13-45 \%$ children with SLE are having lymphadenopathy. ${ }^{5}$ Neither American College of Rheumatology criteria (ACR criteria) nor the Systemic Lupus International Collaborating Clinics (SLICC) criteria does not include lymphadenopathy as a 
diagnostic criterion. Lymphadenopathy is commonly seeing in children with SLE, but it is being a presenting feature is less frequent. ${ }^{6,7}$ Shapira et al stated that juvenile SLE with lymphadenopathy has more constitutional symptoms, cutaneous manifestations and significant high titres of ds-DNA and low complements levels. ${ }^{8}$

There are vast number of diagnosis for generalized lymphadenopathy, making the exact diagnosis is complex and difficult even for the experienced clinician. In our case the patient was initially investigated for possible lymphoproliferative malignancy until the typical features of SLE manifested. SLE mimicking lymphoma is well documented in the literature, causing delay in diagnosis and initiating appropriate treatment. ${ }^{9}$

When considering treatment, it is much more similar to adult patients with SLE but children and adolescents have problems related to their growth and development. ${ }^{10}$ Hydroxychloroquine is recommended in all pediatric patients with SLE as the anchoring treatment. Conjunction with nonsteroid anti-inflammatory drugs is recommended in patients with musculoskeletal manifestations which was not incorporated into the management of this child because those symptoms were not predominate in her. ${ }^{10}$ Our patient belongs to severe SLE category because of renal and central nervous system manifestations warranting treatment with IV glucocorticoids and monthly IV Cyclophosphamide therapy in par with published systematic reviews on SLE management, which she received accordingly. However, recent emerging evidence suggest adding mycophenolate mofetil to patients with lupus nephritis is superior to IV cyclophosphamide. ${ }^{11}$

Early diagnosis of SLE is the key to optimum management and better outcome of the patient, because juvenile SLE has more aggressive disease course, greater morbidity and mortality than adult onset disease. ${ }^{10}$ Diffuse lymphadenopathy as the presenting symptom of SLE is not common today, however it should not be forgotten as in our case to avoid delay in making the diagnosis.

\section{References}

1. Gottlieb, B.S. and Ilowite, N.T., 2006. Systemic lupus erythematosus in children and adolescents. Pediatrics in review, 27(9), p.323.

2. Yu C, Gershwin ME, Chang C. Diagnostic criteria for systemic lupus erythematosus: a critical review. Journal of autoimmunity. 2014 Feb 1;48:10-3.

3. Kamphuis S, Silverman ED. Prevalence and burden of pediatric-onset systemic lupus erythematosus. Nat Rev Rheumatol. 2010;6:538-46.

4. Rosenbaum E, Krebs $E$, Cohen $M$, et al. The spectrum of clinical manifestations, outcome and treatment of pericardial tamponade in patients with systemic lupus erythematosus: a retrospective study and literature review. Lupus 2009;6:608-12

5. Shrestha D, Dhakal AK, Shiva RK, Shakya A, Shah SC, Shakya H. Systemic lupus erythematosus and granulomatous lymphadenopathy. BMC Pediatr. 2013;13:179.doi: 10.1186/1471-2431-13179.

6. Hiraki LT, Benseler SM, Tyrrell PN, et al. Clinical and laboratory characteristics and long-term outcome of pediatric systemic lupus erythematosus: a longitudinal study. J Pediatr. 2008;152:550-6.

7. Ramirez Gomez LA, Uribe Uribe O, Osio Uribe O, et al. Childhood systemic lupus erythematosus in Latin America. The GLADEL experience in 230 children. Lupus. 2008;17:596-604. 
8. Shapira Y, Weinberger A, Wysenbeek AJ. Lymphadenopathy in systemic lupus erythematosus. Prevalence and relation to disease manifestations. ClinRheumatol. 1996;15(4):335-338. doi: 10.1007/BF02230354.

9. Gillmore R, Sin WY. Systemic lupus erythematosus mimicking lymphoma: the relevance of the clinical background in interpreting imaging studies. BMJ Case Rep. 2014;2014

10. Fanouriakis A, Bertsias G. Changing paradigms in the treatment of systemic lupus erythematosus. Lupus Science \& Medicine 2019;6:e000310. doi: 10.1136/lupus-2018-000310

11. Tunnicliffe DJ, Palmer SC, Henderson L, Masson P, Craig JC, Tong A, Singh-Grewal D, Flanc RS, Roberts MA, Webster AC, Strippoli GFM. Immunosuppressive treatment for proliferative lupus nephritis. Cochrane Database of Systematic Reviews 2018, Issue 6. Art. No.: CD002922. 